\title{
Brain Organoids: Human Neurodevelopment in a Dish
}

\author{
Silvia Benito-Kwiecinski and Madeline A. Lancaster \\ MRC Laboratory of Molecular Biology, Cambridge Biomedical Campus, Cambridge CB2 0QH, United Kingdom \\ Correspondence: mlancast@mrc-Imb.cam.ac.uk
}

The human brain is often described as the most complex organ in our body. Because of the limited accessibility of living brain tissue, human-specific features of neurodevelopment and disease remain largely unknown. The ability of induced pluripotent stem cells to self-organize into 3D brain organoids has revolutionized approaches to studying brain development in vitro. This review will first look at the history of studying neural development in a dish and how organoids came to be. We evaluate the ability of brain organoids to recapitulate key developmental events, focusing on the generation of various regional identities, cytoarchitecture, cell diversity, features of neuronal maturation, and circuit formation. We also consider the limitations of the model and review recent approaches to improve reproducibility and the healthy maturation of brain organoids.

C entral to developmental biology is the remarkable ability of one fertilized egg to reliably generate a whole complex body through carefully orchestrated spatial and temporal patterns that generate an immense diversity of cell fates. All living multicellular organisms rely on the ability of a single cell to self-organize into 3D tissues with many specialized cell types, functions, and architectures. Because the instructions to carry out these complex morphogenetic events are contained within each cell, these processes can be recapitulated in vitro with the right starting cell type and culture conditions. Stem cells, or organ progenitors, provide the starting point, while recent improvements in tissue engineering and $3 \mathrm{D}$ culture techniques enable the formation of macrostructures reminiscent of human organs. These so-called organoids are $3 \mathrm{D}$ tissues that self-organize into a spatially or- ganized structure consisting of multiple organspecific cell types in a manner highly reminiscent to the actual organ. Furthermore, because of their embryonic identity and fate potential, pluripotent stem cell (PSC)-derived organoids model developmental trajectories with surprisingly minimal extrinsic guidance leading to spontaneous self-organization into specific early organ structures.

Because PSC-derived organoids follow primarily intrinsic developmental programs, these methods are less like tissue engineering and more akin to gardening. The PSC can be thought of as the seed, while culture conditions resemble the sunlight, soil, fertilizer, and water that nurture the seed to take root and sprout. Thus, these in vitro models are grown rather than built. Because of their intrinsic ontogeny, organoids offer the unprecedented ability to ob-

Editors: Cristina Lo Celso, Kristy Red-Horse, and Fiona M. Watt

Additional Perspectives on Stem Cells: From Biological Principles to Regenerative Medicine available at www.cshperspectives.org

Copyright (C) 2020 Cold Spring Harbor Laboratory Press; all rights reserved; doi: 10.1101/cshperspect.a035709

Cite this article as Cold Spring Harb Perspect Biol 2020;12:a035709 
serve, analyze, and manipulate human development in a dish.

In this context, the human brain in particular is of great interest because of the widespread health burden of neurodevelopmental and neurological disorders, the uniqueness of our exceptionally large primate brains, and the ethical and technical inaccessibility of functionally testing features of human brain development in vivo. Although not the focus of this review, brain organoids have already been used to study various aspects of neurodevelopmental diseases and evolution, and we direct the reader to other reviews covering such work (Clevers 2016; Giandomenico and Lancaster 2017; Qian et al. 2019). This review will focus on neural organoids, covering the history and development of methods for studying in vitro self-organization of neural tissues. We will compare various stages of in vitro development to in vivo development, mainly focusing on methods for generating organoids with cortical identities and furthering their developmental potential.

\section{HISTORY}

\section{Reaggregates}

The remarkable ability of cells to self-organize into 3D tissues in vitro was already observed over a century ago. In 1907, Wilson demonstrated that dissociated sea sponges would reaggregate into complete organisms. This regeneration of a whole animal from its dissociated cells was subsequently shown in other simple organisms (Wilson 1907, 1911; Child 1928). These findings led to a surge of in vitro experiments in the $1950 \mathrm{~s}$ and 1960s looking at how distinct combinations of dissociated cells from more complex organisms would reaggregate into organized structures. In 1955, Townes and Holtfreter (Steinberg and Gilbert 2004) showed that dissociated cells from the three germ layers of early amphibian embryos would recombine into spatially segregated germ layers, reproducing their proper embryonic positions. This reaggregation of cells into organized structures was also shown using cells from later vertebrate embryos, in particular, the chick. Dispersed cells from an already func- tioning vertebrate organ, such as skin or kidney, can under the right conditions self-assemble to reconstitute the tissue (Moscona and Moscona 1952; Weiss and Taylor 1960).

These dissociation-reaggregation experiments showed that tissue formation can occur independent of a prepattern and a sequence of preceding developmental events. Despite initially being randomly clustered, reaggregated cells will self-assemble into distinct regions of a tissue through a process of a cell "sorting out." This process is explained by the differential adhesion hypothesis (Steinberg and Roth 1964), whereby cells will rearrange their positions to bind to cells expressing similar cell surface adhesive molecules, resulting in a more thermodynamically stable structure, segregated into domains of cells with differing adhesive strengths. Sorting out of cells is also observable in aggregates of cortical neurons where early postmitotic neurons have been shown to associate with one another (DeLong 1970).

Reaggregates of tissues from the embryonic nervous system, in particular neural retina cells, were shown to result in neuroepithelial cells selforganizing into radial rosette structures reminiscent of the embryonic neural tube (Moscona 1957; Ishii 1966). Reaggregates derived from early avian retinal cells were not only shown to form rosettes, but these retinal stem cells were also capable of proliferating and differentiating into various retinal cells types, resulting in retinal layers (Vollmer et al. 1984; Rothermel et al. 1997). This demonstrated another level of selforganization observable in vitro as not only could reaggregates sort out cell types into organized structures, but these cells could then maintain their lineage commitment and reproduce features of a developmental program. Similarly, aggregates from embryonic neural precursor cells were also shown to reproduce some basic features of developmental neurogenesis as, after forming neural tube-like structures, neural precursors would proliferate at the lumen and differentiate into neurons destined to an outer layer (Tomooka et al. 1993). Although cells within these aggregates were capable of self-renewing and generating neurons, in terms of modeling brain development, the end organization was 
Brain Organoids

very primitive and did not recapitulate cortical tissue architecture and layering. One key factor in the failure of these $3 \mathrm{D}$ aggregates to model the intricate architecture of the developing brain is likely the developmental stage at which they were taken, which was too late to initiate complex temporal and spatial patterning (Karus et al. 2014), suggesting that more naive cell types might make a better starting point.

\section{Embryonic Stem Cells and Embryoid Bodies}

Embryogenesis can be viewed as a gradual loss of developmental capacity. Soon after fertilization, a blastocyst forms, containing an inner cell mass with PSCs, from which the whole embryo will form through progressive differentiation and specialization into all cell types of the organism. Embryonic stem cells (ESCs) are the pluripotent cells derived from the inner cell mass of a blastocyst (Fig. 1). The ability to culture ESCs has opened many doors to furthering our understanding of developmental biology since, beyond studying specific cells isolated from developing tissue, these PSCs actually provide a tool to watch features of early development and observe differentiation and self-organization into different identities in vitro. When grown in suspension, the ability of ESCs to follow developmental trajectories becomes evident as they aggregate to form small spheres called embryoid bodies (EBs) (Martin 1980, 1981; Evans and Kaufman 1981). EBs essentially mimic the very early events of embryogenesis as, following the blastocyst stage, an embryo will undergo gastrulation and formation of the three germ layers. EBs are capable of mimicking these very early events of embryogenesis as they spontaneously differentiate into the three germ layers-ectoderm, mesoderm, and endoderm (Itskovitz-Eldor et al. 2000) - and thus provide an appealing system for directing early developmental processes in vitro and deriving many tissue and cell types by promoting specific lineages.

\section{Promoting Neural Fates/Neural Rosettes}

The formation of organized neural tissue from EBs was first shown using mouse ESCs (Okabe et al. 1996) and later from human ESCs (hESCs)
(Zhang et al. 2001). These studies showed that when EBs are spread onto an adhesive substrate and directed toward a neural lineage in the presence of bFGF, initially tightly packed epithelial cells change their morphology into elongated neural stem cells that self-organize into $2 \mathrm{D}$ neural rosettes, reminiscent of the embryonic neural tube, radially organized around a lumen.

Insights into key signaling pathways underlying early neural differentiation allowed for the direct differentiation of hESCs and induced pluripotent stem cells (iPSCs) into primitive neural stem cells in 2D monolayer culture, bypassing the EB step by providing a neural-inducing environment. In the absence of caudalizing signals, the default differentiation trajectory for pluripotent cells in the early epiblast is toward anterior neural fates (Levine and Brivanlou 2007). Unless other signaling factors are provided, cells will progress through ectodermal to neuroectodermal, then neuroepithelial and anterior neural states. Signals that induce nonneural identities in the early embryo include Wnts, BMPs, and Nodal and neural differentiation of the ectoderm is achieved by locally suppressing these signals through secretion of inhibitors such as DKK1, Noggin, chordin, and follistatin (Smith and Harland 1992; Sasai et al. 1994; Fainsod et al. 1997; Kazanskaya et al. 2000). In vitro, however, it was found that simply providing adherent mouse ESCs with serum-free minimal media (N2B27 supplements) and eliminating inductive signals for other identities was sufficient to trigger significant differentiation of ES cells into neural precursors, highlighting anterior neural as the default state (Ying et al. 2003). In adherent human ESCs and iPSCs, it was found that inhibition of BMP and TGF- $\beta / N O D A L$ signaling, known as "dual SMAD inhibition" because both pathways use SMADs downstream, destabilizes pluripotency and suppresses nonneural fates, resulting in a more efficient neural induction and the rapid differentiation of cells into early anterior neuroectoderm (Chambers et al. 2009). Neural induction by dual SMAD inhibition resulted in primitive neural stem cells that, despite expressing apical markers at the membrane, lack a polarized expression of these proteins. The addition of bFGF, however, allows 


\section{S. Benito-Kwiecinski and M.A. Lancaster}

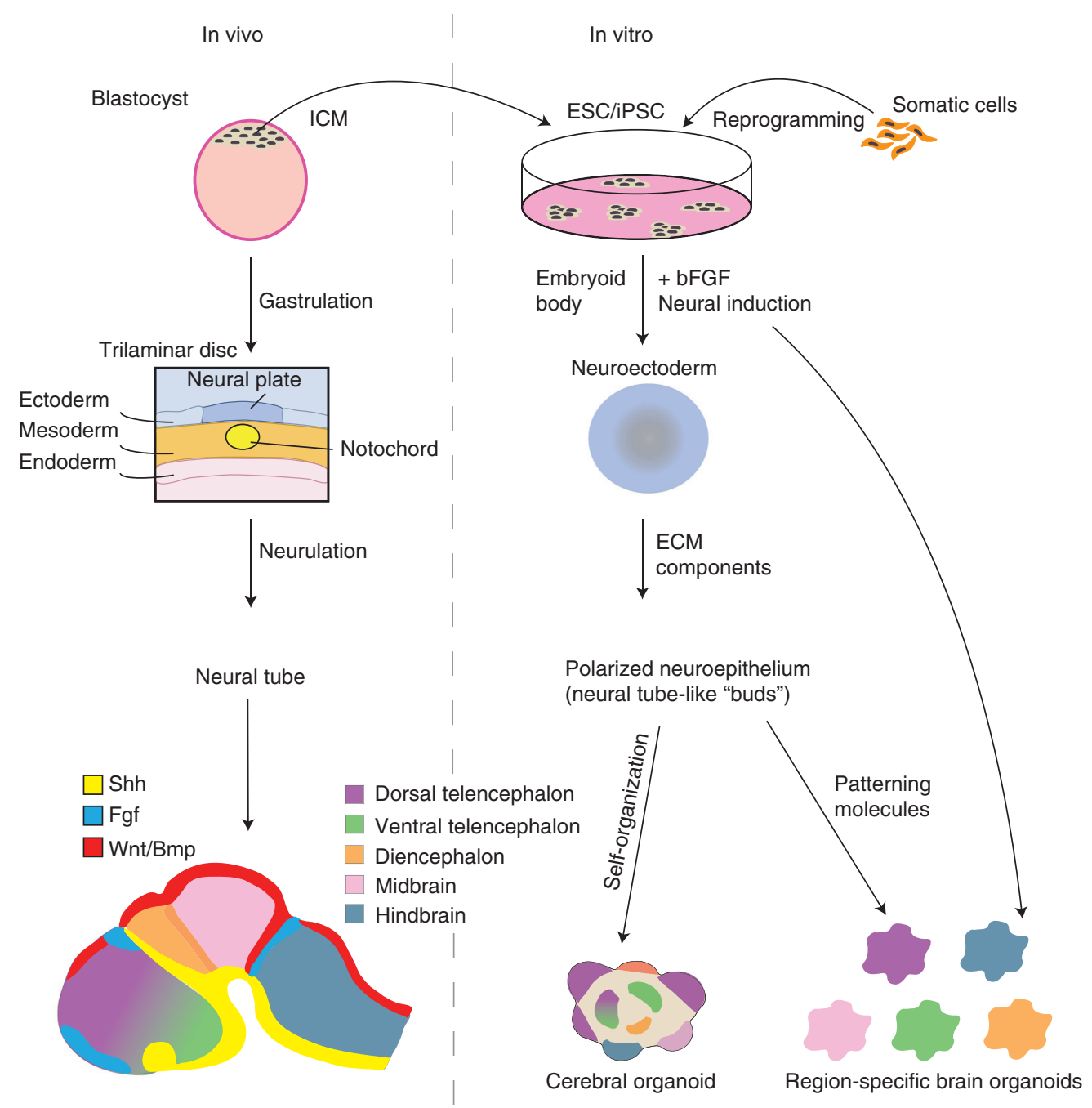

Figure 1. A comparison between in vivo and in vitro brain development. In vivo, the brain develops from the neural plate that folds in on itself to form a neural tube. In vitro, aggregates of embryonic stem (ESCs) or induced pluripotent stem cells (iPSCs) are guided toward a neuroectodermal fate and form neural tube-like buds upon the addition of extracellular matrix (ECM) components. In vivo, the brain is patterned into different regional identities by multiple morphogen gradients (e.g., Fgf, Bmp/Wnt, Shh) along the body axis. In vitro, cerebral organoids will self-organize and self-pattern into various brain regional identities in a heterogeneous manner. Alternatively, signaling molecules can also be added to pattern organoids into specific regional identities. (ICM) inner cell mass.

these primitive neuroepithelial cells to organize into rosette structures ( $\mathrm{Li}$ et al. 2011).

Similar to the developing neural tube, proliferative neuroepithelial cells of the neural rosette are apicobasally polarized, with apically localized proteins such as ZO-1 and aPKC detected at the luminal surface (Shi et al. 2012). Furthermore, these radial glia-like stem cells are pseudostratified and show evidence of interkinetic nuclear migration, with nuclei migrating apically to undergo mitosis. Later, they generate basal TBR2 ${ }^{+}$intermediate progenitors and some mitotic cells are observed more basally along with basal radial glia, suggesting a rough segregation of progenitor zones reminiscent of the ventricular zone (VZ) and subventricular zone 
(SVZ). Rosette neural stem cells are kept in a proliferative state in the presence of mitogenic bFGF, and the withdrawal of bFGF stimulates the onset of neurogenesis in rosette protocols. Remarkably, the temporal order of cortical neurogenesis is maintained in neural rosettes with the sequential generation of neurons in an inside-out pattern, whereby deep layer neurons are generated first, followed by outer layer neurons (Gaspard et al. 2008). These layer-specific neurons were shown to be capable of forming action potentials and excitatory synapses (Shi et al. 2012; Kirwan et al. 2015).

\section{ORGANOID HISTORY}

\section{Moving toward 3D Brain Protocols}

Although neural rosette structures exhibit a high degree of self-organization and recapitulate many important features of early brain development, such as the temporal generation of neurons, these neurons lacked the ability to spatially organize into distinct neuronal layers. It was clear that more accurate modeling of the complex architecture of the developing brain would require $3 \mathrm{D}$ growth. One important movement in this direction was the discovery that EBs could be directed to form primitive neuroectoderm in suspension. This was first shown by culturing mouse EBs in MEDII, a media conditioned from a human hepatocellular carcinoma cell line, resulting in the organization of cells on the surface into a stratified primitive neuroepithelium (Rathjen et al. 2002). In vitro neural differentiation was further improved using more reproducible serum-free methods, known as SFEB (serum-free, floating culture of EBlike aggregates). Aggregates plated on coated dishes would efficiently differentiate into telencephalic progenitors, and subsequent addition of patterning signaling molecules Wnt3a and Shh allowed for directed differentiation into subregional dorsal and ventral telencephalic identities, respectively (Watanabe et al. 2005, 2007). Adapting this method and adding the ROCK inhibitor Y-27632 to promote survival of dissociated human ESCs (Watanabe et al. 2007) as well as allowing for a quicker reaggre- gation of ESCs into EBs using 96-well U-bottom plates (SFEBq) (Eiraku et al. 2008), resulted in the more effective formation of cortical tissue. During the first week of culture, a continuous polarized neuroepithelial sheet would form on the surface of floating EBs, which would eventually self-organize into multiple small rosettes of neural precursors surrounding and growing around apical lumens (Eiraku et al. 2008). Plating of these aggregates onto adherent dishes coated with poly-D-lysine, laminin and fibronectin allowed for telencephalic differentiation and SFEBq rosettes also mimic the development of neural tube-like progenitor zones, generating neurons in a temporally defined manner. When applied to human ESCs, plated SFEBq aggregates were not entirely flattened and appeared "dome-like." Unlike mouse-derived tissues and previous human $2 \mathrm{D}$ rosette protocols, these rosettes for the first time produced much larger and continuous apical lumens, perhaps a reflection of the greatly expanded cortex of humans relative to mice. While recapitulating many early spatial and temporal features of corticogenesis, this semi-3D culture system was, however, still not sufficient to observe the spatial organization of neuronal subtypes into discrete layers.

\section{ECM Gels and the Formation of the First 3D Neural Organoids}

Pivotal to the progression of the wider organoid field was the addition of an extracellular matrix (ECM) hydrogel, for example Matrigel, a soluble basement membrane-rich extract that forms a $3 \mathrm{D}$ gel at $37^{\circ} \mathrm{C}$, derived from a mouse tumor that produces abundant ECM ( $\mathrm{Li}$ et al. 1987; Kleinman and Martin 2005). Matrigel or more defined collagen gels were shown in 2009 to support the formation of $3 \mathrm{D}$ intestinal organoids from intestinal stem cells or small explants grown in the gel (Ootani et al. 2009; Sato et al. 2009). The combination of physical properties such as rigidity of the gel along with additional signaling cues present in basement membrane ligands of Matrigel means that it can support organoid formation by providing both a scaffold and influencing various biological functions such as tissue polarity and cell migration 
(Long and Huttner 2019). Indeed, the addition of Matrigel at various stages of 3D brain organoid protocols appears to have the effect of rapidly promoting the formation of polarized neural tube-like buds from neuroepithelial tissue.

Adding dissolved Matrigel to EBs guided toward retinal identity was successful in supporting the morphogenesis of an ordered optic cup, the first example of an entirely 3D self-organizing neural tissue (Eiraku et al. 2011). Dissolved Matrigel was subsequently successful in supporting the growth of 3D cortical forebrain tissues from floating SFEBq aggregates (Nasu et al. 2012; Kadoshima et al. 2013). Alternatively, 3D brain architecture could also be supported by embedding EBs in pure droplets of Matrigel (Lancaster et al. 2013). The addition of Matrigel to neural-induced EBs supports the formation of a polarized neuroepithelium with the basal side facing the external ECM-like environment, and also provides the epithelium with the support to undergo subsequent morphogenetic changes. In vivo, the polarized neuroepithelium of the neural plate will fold in on itself to form a rounded neural tube, a pseudostratified neuroepithelium surrounding an apical fluid-filled lumen. Although this folding of the neural plate has not yet been replicated in organoids, Matrigel supports the generation of multiple neural tube-like "buds" in which neuroepithelial cells organize in $3 \mathrm{D}$ around large apical lumens. When comparing cortical regions of organoids to $2 \mathrm{D}$ rosettes, $3 \mathrm{D}$ culture systems show a higher level of spatial organization of proliferative progenitors into a VZ, SVZ, and intermediate zone, followed by neurons with primitive inside-out layering into deep early-born neurons followed by later-born neurons that migrate more superficially (Qian et al. 2016). In vivo, neurons in the developing cortex align radially into a dense band called the cortical plate. Despite the ability of organoids to generate basally migrating cortical neurons capable of primitive layering, the addition of dissolved Matrigel to neurogenic stages of organoid development was found to be crucial for generating a cortical plate (Fig. 2; Kadoshima et al. 2013; Lancaster et al. 2017). This is likely a result of the fact that the ECM of the pial basement membrane, generated by overlying nonneural mesenchyme and thus not present in organoids, has been found to be critical for proper neuronal migration and localization within the neural plate (Halfter et al. 2002).

\section{PATTERNING}

\section{Self-Patterned/Cerebral Organoids}

In the absence of external factors, differentiation into neural fates occurs by default. Building on this, Lancaster et al. (2013) used a relatively simple media for culturing organoids, without the addition of any signaling molecules to the culture. By not directing a specific identity that would restrict the developmental landscape, these organoids spontaneously self-pattern and self-organize into distinct brain regions within the same organoid. Because of the presence of broad regional identities, this method was named cerebral organoids (Fig. 1).

Interestingly, adjacent brain identities within cerebral organoids were not entirely randomly interspersed; there were some neighboring regions separated by clear boundaries mimicking borders found in vivo. The early brain develops from a neuroepithelial sheet that is flanked by multiple organizing centers, responsible for patterning the brain through the secretion of various morphogen gradients. Cells will acquire specific regional identities as a result of their position and the combination of various levels of signaling factors (Fig. 1). Two important telencephalic signaling centers are the hem, which is found at the midline adjacent to the choroid plexus and dorsal telencephalon and promotes dorsal identities through the secretion of BMPs and Wnts, and the antihem, which sits opposite the hem and separates dorsal and ventral telencephalic regions through the expression of various morphogens including Wnt antagonists. Tissue reminiscent of these organizing centers was found in cerebral organoids with ventricular zone-like regions showing abrupt borders between dorsal $\left(\mathrm{TBR}^{+}\right)$and ventral $\left(\mathrm{GSX}^{+}\right)$ forebrain identities as would be found at the antihem, and tissue-positive for Wnt2b and BMP6 (secreted from the hem in vivo) was ob- 
served adjacent to choroid plexus $\left(\mathrm{TTR}^{+}\right.$cuboidal morphology), which was immediately followed by the presence of dorsal telencephalic tissue $\left(\mathrm{TBR}^{+}\right)$(Renner et al. 2017). This demonstrated another level of in vitro self-organization; not only could cerebral organoids develop into complex brain architectures, but without any cues or a body axis for reference, neuroepithelial tissue was also capable of spontaneously setting up signaling centers and developing local tissue patterning.

\section{Patterning Organoids with Small Molecules}

As remarkable as it is to observe the generation of broad regional identities in vitro, it is often desirable to reproducibly and efficiently generate organoids consisting of specific brain areas of interest. To overcome regional heterogeneity and restrict identity to a single brain region, the majority of protocols described to date alter media composition to guide organoid development toward a specific fate. Defined developmental patterning factors, many of which had previously been successfully used in $2 \mathrm{D}$ differentiation protocols, are used to promote specific neural fates generating organoids of various identities from forebrain to midbrain to hindbrain (Fig. 1). "Dual SMAD inhibition" is frequently used to prepattern cells to a neuroectodermal fate through treatment with various combinations of inhibitors of the SMAD pathway downstream from BMP and Nodal signaling. Maintaining these inhibitors of the SMAD pathway on growing EBs results in production of organoids with a higher yield of dorsal forebrain identity (Kadoshima et al. 2013; Paşca et al. 2015; Qian et al. 2016). To promote ventral forebrain identities, initial dual SMAD inhibition may be followed by exposure to $\mathrm{SHH}$ agonists (Bagley et al. 2017; Birey et al. 2017; Xiang et al. 2017), mimicking the gradient observed in vivo of Shh activity from the ventral to dorsal neural tube initially produced by underlying notochord that acts as an organizing center on overlying neural tissue.

In vivo, the neuroepithelium of the dorsomedial telencephalon develops into the hippocampus and choroid plexus under inductive signals from BMP and Wnt. Following the original protocol for generating SFEBq cortical tissue followed by a transient exposure to Wnt and BMP resulted in the development of hippocampal organoids, whereas prolonged exposure induced choroid plexus identity (Sakaguchi et al. 2015).

In addition to optic cup organoids, organoids with other diencephalic identities have also been produced in vitro. Following initial dual SMAD treatment to prepattern EBs to neuroectodermal fates, treatment with caudalizing insulin along with a MAPK/ERK inhibitor to prevent overcaudalization to midbrain fates and BMP7, results in the development of thalamic tissue (Shiraishi et al. 2017; Xiang et al. 2019). Treating EBs with SHH and Wnt3a produced organoids with hypothalamic identity (Qian et al. 2016). By inducing both hypothalamic and nonneural oral ectoderm identities from the same EB, Ozone et al. (2016) were able to generate hormone-producing anterior pituitary tissue, which in vivo emerges from the oral ectoderm through interactions with the overlying hypothalamic epithelium.

To generate midbrain organoids, Qian et al. built on $2 \mathrm{D}$ protocols for generating midbrain dopaminergic neurons. In addition to early treatment with SMAD inhibitors, SHH, FGF8, and a Wnt activator were added to the media resulting in neuroepithelial cells expressing the floorplate precursor marker, FOXA2, which at later stages went on to produce $\mathrm{TH}^{+}$dopaminergic neurons (Qian et al. 2016). Furthermore, Jo et al. (2016) found that these dopaminergic neurons secrete brown-colored granules of neuromelanin. In vivo, these neuromelanin granules have been observed in primates but not mice and similarly they were found to be absent from mouse-derived midbrain organoids (Fig. 2; Jo et al. 2016).

Moving more caudally, cerebellar organoids have also been successfully generated. In addition to SMAD inhibition, treatment with caudalizing FGF2 and insulin was sufficient to induce differentiation into cerebellar plate neuroepithelium that initially formed small rosettes. Subsequent treatment with FGF19, expressed at the midbrain-hindbrain boundary and involved 


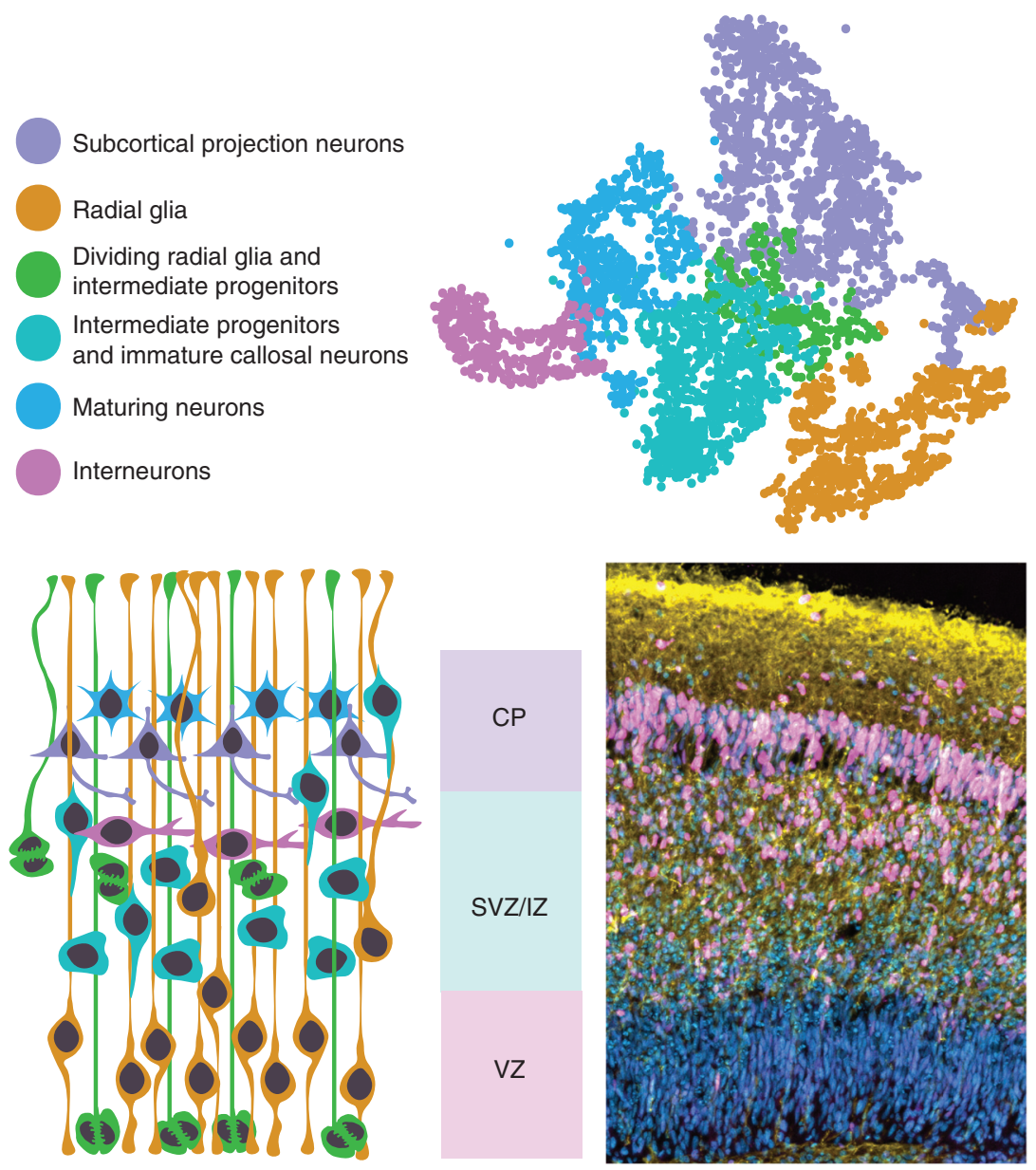

Figure 2. Brain organoids produce various neural cell types that mimic the architecture of the developing brain. (Top row) An example of a tSNE plot generated from scRNA-seq data to visualize various cell identities present in an organoid. (Bottom left) A cartoon image color-coded to represent the various cell types detected by scRNA-seq and their location within the ventricular zone (VZ), subventricular zone (SVZ), intermediate zone (IZ), and cortical plate (CP) of the developing cortical organoid. (Bottom right) A representative image of an organoid containing these architectural and identity divisions stained for DAPI (blue), CTIP2 (magenta), and DCX (yellow).

in the development of dorsal hindbrain progenitors, resulted in the remarkable transformation of cerebellar plate rosettes into large ovalshaped structures, dorsoventrally patterned in a manner reminiscent of the polarized tube structure of early developing human cerebellum. Dorsal region-specific markers were observed on the side of the oval neuroepithelium facing the outside of the whole aggregate, and thus exposed to higher levels of FGF19, whereas ventral markers were expressed on the inner side facing the center of the organoid (Muguruma et al. 2015).

\section{Tradeoff between Heterogeneity versus Uniformity of Organoids}

Something that should be considered more carefully within the organoid field is the tradeoff between heterogeneity versus uniformity of the tissue generated. Although the addition of small molecules and patterning signals to the culture 
directs organoids to desired and reproducible brain identities, several of these small molecules may play roles on developing cells beyond simple patterning and generate desired tissue identities in a manner that does not reflect fetal organogenesis. The addition of excessive external signals runs the risk of flattening the developmental landscape and the intrinsic developmental program of organoids, which could potentially reduce organoid complexity or mask important features of development that might be relevant in the context of a disease. Conversely, organoids that are generated in the absence of patterning molecules, spontaneously self-organizing and self-patterning, suffer from increased "batch-effect" and inconsistent generation of desired tissues, meaning their heterogeneity could potentially conceal subtle disease phenotypes.

Some methods have been able to produce more reproducible brain identities without the addition of external signaling molecules. Growing EBs on floating scaffolds made of fiber microfilaments results in elongated EBs with a larger surface area exposed to neural induction media, resulting in increased neuroectoderm formation and subsequently increased cortical differentiation (Lancaster et al. 2017). Another recent strategy, discussed later in this review, is to generate intrinsic signaling gradients within the organoid, resulting in spatially encoded organoids (Cederquist et al. 2019).

\section{DIFFERENTIATION/MATURATION OF NEURAL CELL TYPES}

\section{D Architecture and Cell Diversity in Organoids}

Brain organoids have the ability to mimic the architecture of the developing brain and form various neural cell types in a spatiotemporal manner. To determine whether these similarities with in vivo brain development occur through the reactivation of developmental gene expression programs, several studies have compared organoid gene expression to primary fetal tissue using microarrays (Paşca et al. 2015), RNA-seq (Mariani et al. 2015; Luo et al. 2016;
Qian et al. 2016), and single-cell RNA-seq (Camp et al. 2015; Quadrato et al. 2017; Sloan et al. 2017; Pollen et al. 2019). These gene expression analyses have shown that organoid protocols replicate early brain development particularly well, generating a wide diversity of cells that share transcriptomic profiles with the early fetal neocortex (Fig. 2). We will focus on how organoids with specifically cortical identity mimic early brain architecture and gene expression programs.

Organoids contain multiple neural tube-like regions that exhibit VZ-like regions populated by proliferative apical progenitors that express typical radial glial marker genes (SOX2, NESTIN, PAX6) and make up the majority of cells in the organoid prior to neurogenesis. These neural stem cells are pseudostratified, display the typical elongated morphology of radial glial cells and undergo mitosis at the apical surface, via interkinetic nuclear migration (Bershteyn et al. 2017). After the onset of neurogenesis, populations of intermediate progenitor cells $\left(\mathrm{TBR} 2^{+}\right)$begin to appear in an SVZ-like region basal to the VZ-like region (Fig. 2). Cells expressing basal radial glial markers (HOPX, PTPRZ1) have also been observed (Qian et al 2016; Li et al. 2017), which are present exclusively in the outer SVZ (oSVZ) in vivo, an additional germinal zone thought to be absent in rodent neocortices (LaMonica et al. 2012). However, although cells expressing oSVZ markers are being generated in organoid protocols, an oSVZ-like region has yet to be observed reliably.

In vivo, neurons generated from $\mathrm{VZ}$ and SVZ regions migrate basally along radial glial processes to the cortical plate and form a sixlayered structure, each composed of neurons with different properties. Neurogenesis occurs in a spatiotemporal manner with deep-layer neurons generated earlier followed by later generations of upper-layer neurons. Although organoid protocols to date only show a restricted spatial layering of neurons, they do generate the various classes of neurons following the temporal trajectory of initially making deep-layer $\left(\mathrm{CTIP}^{+}\right)$, followed by upper-layer $\left(\mathrm{SATB} 2^{+}\right)$ neurons (Renner et al. 2017). 


\section{Neuronal Activity and Maturation}

Several studies have now investigated the physiological properties of neurons generated in organoid protocols and shown their functional maturation over time. Over time, neurons generated in brain organoid protocols begin to functionally mature and exhibit spontaneous firing, shown by $\mathrm{Ca}^{2+}$ surges (Eiraku et al. 2008; Lancaster et al. 2013) and electrophysiological recordings (Qian et al. 2016), with firing frequency sensitive to the application of glutamate and glutamate receptor antagonists, indicating the presence of glutamatergic neurons (Lancaster et al. 2013). Intrinsic glutamate release and levels within cortical organoids have also been measured using enzyme-modified microelectrodes (Nasr et al. 2018).

GABA is known as the major inhibitory neurotransmitter in the brain; however, during development, it exerts a depolarizing effect on immature neurons (Leonzino et al. 2016). One key feature of neuronal maturation is the switch from a depolarizing to a hyperpolarizing response to GABA, mediated in vivo by decreasing intracellular $\mathrm{Cl}^{-}$concentrations as neurons mature because of the down-regulation and up-regulation of NKCC1 and KCC2 membrane transport proteins, respectively. Qian et al. (2016) found that organoids also appear to replicate this neuronal maturation by showing increased expression of $\mathrm{KCC} 2$ and a reduction in neurons responsive to GABA-induced depolarization as organoids mature.

\section{Circuit Formation}

Single labeling of neurons generated by organoids demonstrates the ability of these neurons to generate complex morphologies and synapse onto each other, with dendritic spines in close proximity to presynaptic terminals (Qian et al. 2016).

Serial electron microscopy of older organoids (Quadrato et al. 2017) further showed the ability of neurons to form synapses, revealing a density of synapses within the range of densities observed in human fetal brains (Huttenlocher and Dabholkar 1997). Also observed were single dendrites making synapses with multiple axons, suggesting the formation of complex networks. In addition to confirming spontaneous firing activity in individual neurons, Quadrato et al. measured population firing activity and found some organoids that displayed clear bursts of coordinated activity, indicating that organoids are capable of generating neuronal networks that form self-organized firing patterns.

Additionally, they found that organoids cultured long-term generated a population of lightsensing retinal cells, photoreceptors. These photoreceptors were functional as a subpopulation of neurons showed attenuation in firing rates in response to light exposure. The capability of organoids to respond to physiological sensory input suggests that organoids may be used in the future to study how circuit formation and network activity is regulated by sensory stimuli.

Recently, organoids cultured at the air-liquid interface (ALI-CO) (Giandomenico et al. 2019) were able to show a great improvement in survival and maturation of neurons that were capable of forming long, dense bundles of axons with specific orientations, reminiscent of nerve tracts. In vivo, deep-layer neurons of the cortex project axons subcortically to other regions of the brain, whereas upper-layer neurons project intracortically and form callosal tracts. Two main morphologies of axon tracts reminiscent of callosal and subcortical projections were observed in ALI-COs: ones that projected internally within the organoid and others that projected outwardly and away from the organoid altogether, formed by neurons with a primarily upperlayer $\left(\mathrm{CUX}^{+}\right)$and deep-layer $\left(\mathrm{CTIP} 2^{+}\right)$identity, respectively. Intracortical-like tracts often made sharp turns along their path and staining for known developmental guidance cues, such as WNT5a, revealed its presence surrounding axon tracts, demonstrating the ability of organoids to self-organize axonal pathways. Measuring neuronal activity across the ALI-COs showed correlated firing activity between regions at various distances, demonstrating that functional intracortical-like connections produce short-, medium-, and long-range connectivity within the organoid. To test the functional output of escaping subcortical-like tracts, ALICOs were cocultured with dissected embryonic 
mouse spinal cord still attached to peripheral nerves and perispinal muscles. Escaping axon tracts were able to innervate the spinal cord and trigger coordinated contractions of the muscles. Furthermore, muscle contractions could be controlled by extracellular stimulation of axon tracts and the latency of response between stimulation and contraction was similar to latencies recorded in developing human descending motor pathways.

The experiments performed by Quadrato et al. and Giandomenico et al. show functional sensory input and motor output of organoids, meaning that organoids could be used to study neural connectivity, potentially between different brain region-specific organoids assembled together, as discussed further below.

\section{Other Neural Cell Types}

Neurons are not the only cell types necessary to make a brain. Glial cells are essential for brain functioning in late development and the adult brain, making up at least half of human brain cells. The two main glial cells, astrocytes and oligodendrocytes, are essential for supporting synaptic function and rapid transmission of nerve impulses, respectively. These cell types arise in late embryonic development, beginning in the middle of the second trimester and continuing after birth, when the same neural progenitors that were undergoing neurogenesis switch from a primarily neurogenic to gliogenic fate (Jiang and Nardelli 2016).

Immunostaining of organoids cultured long-term reveals GFAP-expressing cells with the typical stellar-like morphologies of astrocytes (Paşca et al. 2015; Renner et al. 2017). Astrocyte-like cells isolated from cortical organoids were capable of recapitulating several key functions of astrocytes, with several in vitro assays showing their ability to uptake glutamate, induce synapse formation, phagocytose synaptosomes, and modulate neuronal calcium signaling (Sloan et al. 2017). As astrocytes mature from fetal to postnatal states, they undergo various transcriptomic changes, including changes such as increased morphological complexity, reduced proliferative capacity, and reduced func- tional ability to phagocytose synaptosomes. Sloan et al. showed, by purifying astrocytes from organoids in a time series ranging from 100 to 590 days of culture and performing single-cell RNA sequencing and various functional assays, that these features were replicated in vitro with earlier time points correlating with fetal astrocytes and showing increased proliferative capacities and ability to phagocytose synaptosomes. Later time points (around 400 days of culture) correlated with mature astrocytes and showed more complex morphologies and increased ability to augment calcium signaling in neurons.

Single-cell RNA sequencing has detected a small proportion of cells that express oligodendrocyte precursor cell (OPC) markers after long-term culture (Quadrato et al. 2017; Giandomenico et al. 2019). This makes sense as the formation of myelin sheaths around axons by mature oligodendrocytes only begins around birth in vivo. To study oligodendrogenesis in vitro, Madhavan et al. (2018) exposed cortical spheroids to known oligodendrocyte lineage growth factors and hormones to promote OPC proliferation and further maturation into myelinating oligodendrocytes that were capable of forming myelin sheaths wrapped around axons within the neurosphere. Kim et al. (2019) also used a protocol to accelerate oligodendrocyte maturation and demonstrated differences in the timing of oligodendrogenesis and maturation when the protocol was applied to ventral versus dorsal patterned forebrain organoids. These differences mimicked in vivo observations in mice, where ventral neural precursors undergo a wave of oligodendrogenesis prior to the dorsal wave (Kessaris et al. 2006). Prolonged culture past initial oligodendrocyte maturation in both these studies, however, did not lead to continued structural organization of myelin sheaths such as myelin compaction and formation of nodes of Ranvier, potentially caused by the lack of mature neurons and network activity, necessary to signal and drive myelination (Almeida and Lyons 2017), or caused by the lack of nutrients exposed to oligodendrocytes in these 3D models. Perhaps promoting oligodendrocyte lineages in slice cultured organoids grown at the 
air-liquid interface would allow for further maturation of myelin sheaths in a system with increased nutrient exposure and cell survivability, in addition to more mature network formation.

Microglia are the resident innate immune cells of the brain that have also been shown to have roles in fine-tuning neuronal circuits and regulating neural progenitor cell number (Cunningham et al. 2013). Microglia arise from extraembryonic and mesoderm lineages and are therefore usually absent from brain organoid protocols that primarily or exclusively contain neuroectodermal lineage. However, a completely undirected cerebral organoid protocol, which produces less consistent brain regions by not manipulating molecular patterning pathways, does produce a proportion of mesoderm progenitor cells that develop into microglia-like cells (Ormel et al. 2018). Another study found that microglia-like cells differentiated from iPSCs could enter and integrate in brain organoids simply by adding them to the culturing media (Abud et al. 2017). Furthermore, upon injury to the organoid these microglia-like cells changed their morphology to resemble activated microglia found in diseased or injured brains.

\section{IMPROVEMENTS/ENGINEERING}

\section{Cell Survival and Maturation}

In early brain development, neural tube formation, proliferation, and neurogenesis occur in the absence of vascularization. Eventually, as the tissue grows and thickens, vascularization becomes essential. In vivo organs consist of vast branched vascular networks, and cells are within a few hundred micrometers of a capillary allowing for diffusion. Vascular networks, being of nonneural origin, are not formed in organoids, impairing cell survivability and architecture in older, larger organoids. Culturing organoids in agitation on a shaker or in spinning bioreactors (Lancaster et al. 2013; Qian et al. 2016; Sutcliffe and Lancaster 2017) can increase their diffusion limit; however, organoids will usually reach a maximum size of $\sim 5-6 \mathrm{~mm}$ and consist of a necrotic core because of the lack of vascularization, limiting the supply of oxygen and nutrients to the core of the organoid. As described above, slice cultures of organoids can overcome issues involving lack of nutrient supply, massively improving cell survival and maturation (Fig. 3; Giandomenico et al. 2019).

An alternative approach to address this issue of vascularization was tested by Mansour et al. (2018) through transplanting brain organoids into the adult mouse brain. The host vascular system was capable of invading and nourishing the organoid with active blood flow. This resulted in a replacement of the necrotic core with healthy mature neurons (Fig. 3). Furthermore, these organoids also integrated host microglia. This transplantation approach enables vascularization more similar to what would occur in vivo and opens avenues to studying the interaction of organoids with microglia and immune cells; however, it does involve a surgical procedure and damage to the host, and the growth of the organoid is limited by the size of the cavity in the mouse cortex. It will be interesting to accomplish in vitro vascularization in a manner that does not disrupt the self-organizing architecture of brain organoids. This may be achieved by coculturing organoids with endothelial precursors. Perhaps the brain organoid field may borrow vascularization approaches from other organoid systems, for example, the vascularized kidney organoids developed by Homan et al. (2019), by culturing them under flow on microfluidic chips with endothelial cells, which resulted in the generation of vascular networks.

\section{Assembled Organoids}

The fact that we are capable of directing and generating a multitude of brain regions in vitro brings the exciting prospect of combining them to form more complex structures to study connectivity and interactions between different brain regions.

In cerebral organoids, it was shown that different brain regions within the same organoid might be interacting in a manner similar to in vivo as GABAergic interneurons originating from ventral forebrain were frequently detected in dorsal forebrain regions of organoids con- 


\section{Engineering brain organoids}

\section{Patterning}

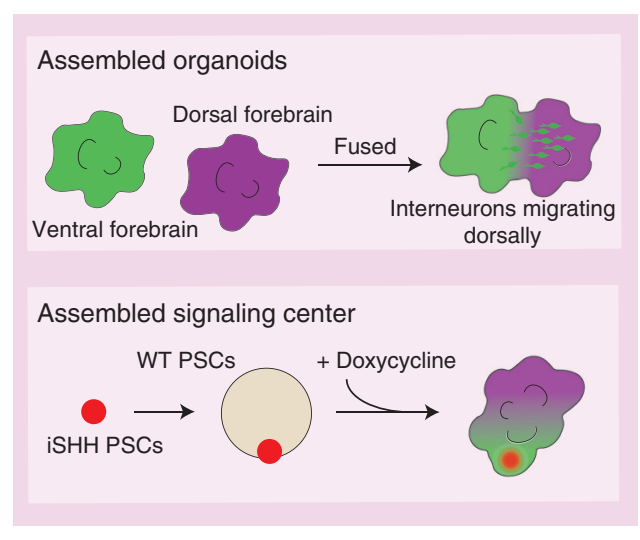

Cell survival and maturation

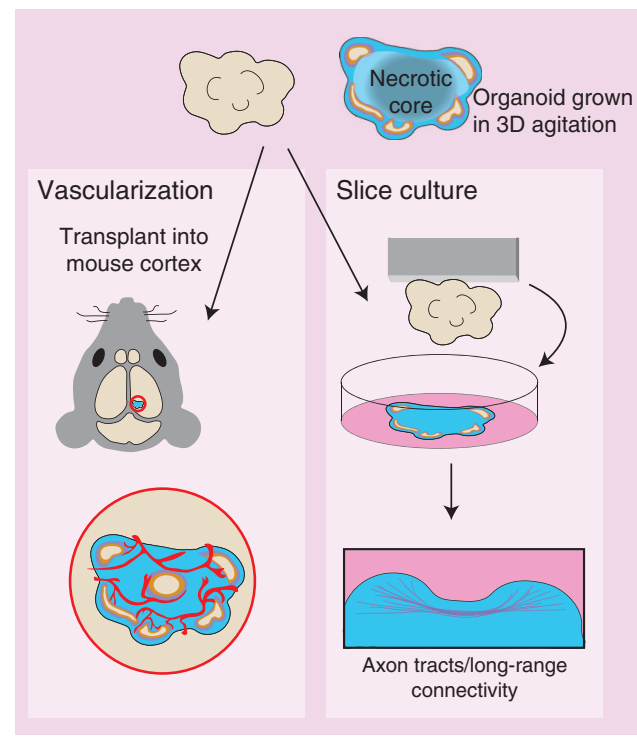

Figure 3. Methods in use for engineering brain organoids. (Left panel) Patterned organoids can be made by fusing organoids of different regional identities to one another or by generating organoids containing a region of transgenic cells expressing an inducible signaling molecule that produces spatially patterned organoids. (Right panel) Organoids grown in vitro in 3D suffer from a necrotic core that impairs their maturation as a result of diffusion limits and a lack of vasculature. Transplanting organoids into the adult mouse cortex allows healthy neural tissue to form in the core of the organoid. Growing organoids as slice cultures improves neuronal survival and maturation and allows for the formation of long axon tracts connecting different regions or tissues. (WT) wild type, (PSC) pluripotent stem cell.

taining both tissues. This suggests a ventral-todorsal migration of these neurons, similar to the developing forebrain where interneurons are integrated into cortical circuits (Lancaster et al. 2013). Building on these observations, several studies have fused region-specific dorsal and ventral forebrain organoids to each other to study the saltatory migration of interneurons from the ventral organoid into the dorsal organoid (Fig. 3; Bagley et al. 2017; Birey et al. 2017; Xiang et al. 2017). Furthermore, it was shown that interneurons that had migrated altered their morphology, made synapses with dorsal glutamatergic neurons, and formed electrically active functional cortical microcircuits (Birey et al. 2017). These fusions are achieved by close positioning of the two organoids in a microwell or tube for a few days (Birey et al. 2017; Xiang et al. 2017) or by embedding two EBs in the same droplet of Matrigel after patterned neural induction (Bagley et al. 2017).
Cortical organoids have also been fused to thalamic organoids (Xiang et al. 2019). These fused organoids form reciprocal thalamocortical and corticothalamic projections, with thalamocortical projections found to innervate regions of cortical organoids containing differentiated neurons. Electrophysiological recording of thalamic neurons revealed an increased firing frequency of neurons in fused organoids versus thalamic organoids alone.

\section{Assembling Signaling Centers}

Recently, Cederquist et al. (2019) developed a system to induce a morphogen gradient from one pole of a developing forebrain organoid, mimicking developmental organizing centers, and resulting in organoids with spatially encoded forebrain subdivisions similar to fetal patterning (Fig. 3). First, a small aggregate of ESCs expressing inducible $\mathrm{SHH}$ is allowed to 
form, and then a larger amount of ESCs is seeded on top, resulting in an EB with an aggregate of organizer cells at one pole of the developing organoid. This asymmetric SHH cue mimicked ventral-high and dorsal-low SHH gradients, resulting in the self-organization of a dorsoventral forebrain axis with ventral identities appearing nearer to and dorsal identities further from the organizer cells.

\section{CONCLUSION AND FUTURE PROSPECTS}

The ability to generate various ordered brain regions with remarkably little external input demonstrates the outstanding capacity of stem cells to carry out an intrinsic program involving multiple stages of complex tissue movements, differentiation, and cell interactions. Despite undergoing development in a dish, outside of their natural environment, brain organoid protocols are capable of recapitulating many features of early brain development in a spatiotemporal manner, both in terms of gene expression and cytoarchitecture.

The past few years have witnessed major breakthroughs in brain organoid development and tissue engineering, allowing for the generation of a multitude of regional identities and the modeling of later stages of brain development such as neuronal maturation, connectivity, and the formation of functional circuits. The modeling of these later, more complex stages of brain development still has various limitations that are beginning to be addressed, as it involves the interplay of several cell types of nonneural origins and interactions between various brain regions with a predictable topographic organization along the developing body axis. We predict that the coming years will attempt to more reproducibly model these later stages of brain development by optimizing culture conditions to allow for in vitro vascularization and the incorporation of microglia and immune cells in brain organoids. We also predict that additional and more complex types of brain circuits will be modeled by assembling multiple organoids of specific regional identities to one another in a defined orientation. The fact that organoids can self-organize circuits that respond to physiolog- ical stimuli and are capable of innervating mouse spinal cords to evoke functional muscular output, brings the exciting prospect of generating full circuits where a sensory input would trigger a physical output. We think it is important to exercise a certain level of caution when attempting to generate complex brain structures more reproducibly, as overly engineering the development of brain tissue in vitro runs the risk of skipping over key steps in tissue morphogenesis and not faithfully recapitulating the developmental program of brain formation.

\section{ACKNOWLEDGMENTS}

We thank members of the Lancaster laboratory for helpful insight. We also apologize to those colleagues whose work could not be covered because of space constraints. Work in the Lancaster laboratory is supported by the Medical Research Council (MC_UP_1201/9) and the European Research Council (ERC STG 757710).

\section{REFERENCES}

Abud EM, Ramirez RN, Martinez ES, Healy LM, Nguyen CHH, Newman SA, Yeromin AV, Scarfone VM, Marsh SE, et al. 2017. iPSC-derived human microglia-like cells to study neurological diseases. Neuron 94: 278-293.e9. doi:10.1016/j.neuron.2017.03.042

Almeida RG, Lyons DA. 2017. On myelinated axon plasticity and neuronal circuit formation and function. J Neurosci 37: 10023-10034. doi:10.1523/jneurosci.3185-16.2017

Bagley JA, Reumann D, Bian S, Lévi-Strauss J, Knoblich JA. 2017. Fused cerebral organoids model interactions between brain regions. Nat Methods 18: 170-751.

Bershteyn M, Nowakowski TJ, Pollen AA, Di Lullo E, Nene A, Wynshaw-Boris A, Kriegstein AR. 2017. Human iPSCderived cerebral organoids model cellular features of lissencephaly and reveal prolonged mitosis of outer radial glia. Cell Stem Cell 20: 435-449.e4. doi:10.1016/j.stem .2016.12.007

Birey F, Andersen J, Makinson CD, Islam S, Wei W, Huber N, Fan HC, Metzler KRC, Panagiotakos G, Thom N, et al. 2017. Assembly of functionally integrated human forebrain spheroids. Nature 545: 54-59. doi:10.1038/na ture22330

Camp JG, Badsha F, Florio M, Kanton S, Gerber T, WilschBräuninger M, Lewitus E, Sykes A, Hevers W, Lancaster M, et al. 2015. Human cerebral organoids recapitulate gene expression programs of fetal neocortex development. Proc Natl Acad Sci 112: 15672-15677.

Cederquist GY, Asciolla JJ, Tchieu J, Walsh RM, Cornacchia D, Resh MD, Studer L. 2019. Specification of positional 
identity in forebrain organoids. Nat Biotechnol 37: 436444. doi:10.1038/s41587-019-0085-3

Chambers SM, Fasano CA, Papapetrou EP, Tomishima M, Sadelain M, Studer L. 2009. Highly efficient neural conversion of human ES and iPS cells by dual inhibition of SMAD signaling. Nat Biotechnol 27: 275-280. doi:10 $.1038 /$ nbt. 1529

Child C. 1928. Axial development in aggregates of dissociated cells from Corymorpha palma. Physiol Zool 1: 419461. doi:10.1086/physzool.1.3.30151056

Clevers H. 2016. Modeling development and disease with organoids. Cell 165: 1586-1597. doi:10.1016/j.cell.2016 .05 .082

Cunningham CL, Martínez-Cerdeño V, Noctor SC. 2013. Microglia regulate the number of neural precursor cells in the developing cerebral cortex. J Neurosci 33: 42164233. doi:10.1523/jneurosci.3441-12.2013

DeLong GR. 1970. Histogenesis of fetal mouse isocortex and hippocampus in reaggregating cell cultures. Dev Biol 22: 563-583. doi:10.1016/0012-1606(70)90169-7

Eiraku M, Watanabe K, Matsuo-Takasaki M, Kawada M, Yonemura S, Matsumura M, Wataya T, Nishiyama A, Muguruma K, Sasai Y. 2008. Self-organized formation of polarized cortical tissues from ESCs and its active manipulation by extrinsic signals. Cell Stem Cell 3: 519-532. doi:10.1016/j.stem.2008.09.002

Eiraku M, Takata N, Ishibashi H, Kawada M, Sakakura E, Okuda S, Sekiguchi K, Adachi T, Sasai Y. 2011. Self-organizing optic-cup morphogenesis in three-dimensional culture. Nature 472: 51-56. doi:10.1038/nature09941

Evans MJ, Kaufman M. 1981. Establishment in culture of pluripotential stem cells from mouse embryos. Nature 292: 151-156.

Fainsod A, Deißler K, Yelin R, Marom K, Epstein M, Pillemer G, Steinbeisser H, Blum M. 1997. The dorsalizing and neural inducing gene follistatin is an antagonist of BMP-4. Mech Dev 63: 39-50. doi:10.1016/S0925-4773 (97)00673-4

Gaspard N, Bouschet T, Hourez R, Dimidschstein J, Naeije G, van den Ameele J, Espuny-Camacho I, Herpoel A, Passante L, Schiffmann SN, et al. 2008. An intrinsic mechanism of corticogenesis from embryonic stem cells. Nature 455: 351-357. doi:10.1038/nature07287

Giandomenico SL, Lancaster MA. 2017. Probing human brain evolution and development in organoids. Curr Opin Cell Biol 44: 36-43. doi:10.1016/j.ceb.2017.01.001

Giandomenico SL, Mierau SB, Gibbons GM, Wenger LMD, Masullo L, Sit T, Sutcliffe M, Boulnger J, Tripodi M, Derivery E, et al. 2019. Cerebral organoids at the air-liquid interface generate diverse nerve tracts with functional output. Nat Neurosci 22: 669-679. doi:10.1038/s41593019-0350-2

Halfter W, Dong S, Yip YP, Willem M, Mayer U. 2002. A critical function of the pial basement membrane in cortical histogenesis. J Neurosci 22: 6029-6040. doi:10.1523/ jneurosci.22-14-06029.2002

Homan KA, Gupta N, Kroll KT, Kolesky DB, Skylar-Scott M, Miyoshi T, Mau D, Valerius MT, Ferrante T, Bonvenre JV, et al. 2019. Flow-enhanced vascularization and maturation of kidney organoids in vitro. Nat Methods 16: 255262. doi:10.1038/s41592-019-0325-y
Huttenlocher PR, Dabholkar AS. 1997. Regional differences in synaptogenesis in human cerebral cortex. J Comp Neurol 387: 167-178. doi:10.1002/(SICI)1096-9861 (19971020)387:2<167::AID-CNE1>3.0.CO;2-Z

Ishii K. 1966. Reconstruction of dissociated chick brain cells in rotation-mediated culture. Cytologia 31: 89-98. doi:10 $.1508 /$ cytologia. 31.89

Itskovitz-Eldor J, Schuldiner M, Karsenti D, Eden A, Yanuka O, Amit M, Soreq H, Benvenisty N. 2000. Differentiation of human embryonic stem cells into embryoid bodies comprising the three embryonic germ layers. Mol Med 6: 88-95. doi:10.1007/BF03401776

Jiang X, Nardelli J. 2016. Cellular and molecular introduction to brain development. Neurobiol Dis 92: 3-17. doi:10 1016/j.nbd.2015.07.007

Jo J, Xiao Y, Sun AX, Cukuroglu E, Tran HD, Göke J, Tan ZY, Saw TY, Tan CP, Lokman H, et al. 2016. Midbrain-like organoids from human pluripotent stem cells contain functional dopaminergic and neuromelanin-producing neurons. Cell Stem Cell 19: 248-257. doi:10.1016/j.stem 2016.07.005

Kadoshima T, Sakaguchi H, Nakano T, Soen M, Ando S, Eiraku M, Sasai Y. 2013. Self-organization of axial polarity, inside-out layer pattern, and species-specific progenitor dynamics in human ES cell-derived neocortex. Proc Natl Acad Sci 110: 20284-20289. doi:10.1073/pnas .1315710110

Karus M, Blaess S, Brüstle O. 2014. Self-organization of neural tissue architectures from pluripotent stem cells. J Comp Neurol 522: 2831-2844. doi:10.1002/cne.23608

Kazanskaya O, Glinka A, Niehrs C. 2000. The role of Xenopus dickkopf1 in prechordal plate specification and neural patterning. Development 127: 4981-4992.

Kessaris N, Fogarty M, Iannarelli P, Grist M, Wegner M, Richardson WD. 2006. Competing waves of oligodendrocytes in the forebrain and postnatal elimination of an embryonic lineage. Nat Neurosci 9: 173-179. doi:10 $.1038 / \mathrm{nn} 1620$

Kim H, Xu R, Padmashri R, Dunaevsky A, Liu Y, Dreyfus CF, Jiang P. 2019. Pluripotent stem cell-derived cerebral organoids reveal human oligodendrogenesis with dorsal and ventral origins. Stem Cell Rep 12: 890-905. doi:10 $.1016 /$ j.stemcr.2019.04.011

Kirwan P, Turner-Bridger B, Peter M, Momoh A, Arambepola D, Robinson HPC, Livesey FJ. 2015. Development and function of human cerebral cortex neural networks from pluripotent stem cells in vitro. Development 142: 3178-3187. doi:10.1242/dev.123851

Kleinman HK, Martin GR. 2005. Matrigel: basement membrane matrix with biological activity. Semin Cancer Biol 15: 378-386. doi:10.1016/j.semcancer.2005.05.004

LaMonica BE, Lui JH, Wang X, Kriegstein AR. 2012. OSVZ progenitors in the human cortex: an updated perspective on neurodevelopmental disease. Curr Opin Neurobiol 22: 747-753. doi:10.1016/j.conb.2012.03.006

Lancaster MA, Renner M, Martin CA, Wenzel D, Bicknell LS, Hurles ME, Homfray T, Penninger JM, Jackson AP, Knoblich JA. 2013. Cerebral organoids model human brain development and microcephaly. Nature 501: 373379. doi:10.1038/nature12517

Lancaster MA, Corsini NS, Wolfinger S, Gustafson EH, Phillips AW, Burkard TR, Otani T, Livesey FJ, Knoblich 
JA. 2017. Guided self-organization and cortical plate formation in human brain organoids. Nat Biotechnol 11: 546-666.

Leonzino M, Busnelli M, Antonucci F, Verderio C, Mazzanti M, Chini B. 2016. The timing of the excitatory-to-inhibitory GABA switch is regulated by the oxytocin receptor via KCC2. Cell Rep 15: 96-103. doi:10.1016/j.celrep.2016 .03 .013

Levine AJ, Brivanlou AH. 2007. Proposal of a model of mammalian neural induction. Dev Biol 308: 247-256. doi:10.1016/j.ydbio.2007.05.036

Li ML, Aggeler J, Farson DA, Hatier C, Hassell J, Bissell MJ. 1987. Influence of a reconstituted basement membrane and its components on casein gene expression and secretion in mouse mammary epithelial cells. Proc Natl Acad Sci 84: 136-140. doi:10.1073/pnas.84.1.136

Li W, Sun W, Zhang Y, Wei W, Ambasudhan R, Xia P, Talantova M, Lin T, Kim J, Wang X, et al. 2011. Rapid induction and long-term self-renewal of primitive neural precursors from human embryonic stem cells by small molecule inhibitors. Proc Natl Acad Sci 108: 8299-8304. doi:10.1073/pnas.1014041108

Li Y, Muffat J, Omer A, Bosch I, Lancaster MA, Sur M, Gehrke L, Knoblich JA, Jaenisch R. 2017. Induction of expansion and folding in human cerebral organoids. Cell Stem Cell 20: 385-396.e3. doi:10.1016/j.stem.2016 .11 .017

Long KR, Huttner WB. 2019. How the extracellular matrix shapes neural development. Open Biol 9: 180216. doi:10 $.1098 /$ rsob. 180216

Luo C, Lancaster MA, Castanon R, Nery JR, Knoblich JA, Ecker JR. 2016. Cerebral organoids recapitulate epigenomic signatures of the human fetal brain. Cell Rep 17: 3369-3384. doi:10.1016/j.celrep.2016.12.001

Madhavan M, Nevin ZS, Shick HE, Garrison E, ClarksonParedes C, Karl M, Clayton BLL, Factor DC, Allan KC, Barbar L, et al. 2018. Induction of myelinating oligodendrocytes in human cortical spheroids. Nat Methods 15: 700-706. doi:10.1038/s41592-018-0081-4

Mansour AA, Gonçalves JT, Bloyd CW, Li H, Fernandes S, Quang D, Johnston S, Parylak SL, Jin X, Gage FH. 2018. An in vivo model of functional and vascularized human brain organoids. Nat Biotechnol 36: 432-441. doi:10 $.1038 /$ nbt. 4127

Mariani J, Coppola G, Zhang P, Abyzov A, Provini L, Tomasini L, Amenduni M, Szekely A, Palejev D, Wilson M, et al. 2015. FOXG1-dependent dysregulation of GABA/ glutamate neuron differentiation in autism spectrum disorders. Cell 162: 375-390. doi:10.1016/j.cell.2015.06.034

Martin GR. 1980. Teratocarcinomas and mammalian embryogenesis. Science 209: 768-776. doi:10.1126/science .6250214

Martin GR. 1981. Isolation of a pluripotent cell line from early mouse embryos cultured in medium conditioned by teratocarcinoma stem cells. Proc Natl Acad Sci 78: 76347638. doi:10.1073/pnas.78.12.7634

Moscona A. 1957. Formation of lentoids by dissociated retinal cells of the chick embryo. Science 125: 598-599. doi:10.1126/science.125.3248.598

Moscona A, Moscona H. 1952. The dissociation and aggregation of cells from organ rudiments of the early chick embryo. J Anat 86: 287-301.
Muguruma K, Nishiyama A, Kawakami H, Hashimoto K, Sasai Y. 2015. Self-organization of polarized cerebellar tissue in 3D culture of human pluripotent stem cells. Cell Rep 10: 537-550. doi:10.1016/j.celrep.2014.12.051

Nasr B, Chatterton R, Yong JHM, Jamshidi P, D'Abaco GM, Bjorksten AR, Kavehei O, Chana G, Dottori M, Skafidas E. 2018. Self-organized nanostructure modified microelectrode for sensitive electrochemical glutamate detection in stem cells-derived brain organoids. Biosensors 8: E14. doi:10.3390/bios8010014

Nasu M, Takata N, Danjo T, Sakaguchi H, Kadoshima T, Futaki S, Sekiguchi K, Eiraku M, Sasai Y. 2012. Robust formation and maintenance of continuous stratified cortical neuroepithelium by laminin-containing matrix in mouse ES cell culture. PLOS ONE 7: e53024. doi:10 .1371 /journal.pone.0053024

Okabe S, Forsberg-Nilsson K, Spiro AC, Segal M, McKay RDG. 1996. Development of neuronal precursor cells and functional postmitotic neurons from embryonic stem cells in vitro. Mech Dev 59: 89-102. doi:10.1016/ 0925-4773(96)00572-2

Ootani A, Li X, Sangiorgi E, Ho QT, Ueno H, Toda S, Sugihara H, Fujimoto K, Weissman IL, Capecchi MR, et al. 2009. Sustained in vitro intestinal epithelial culture within a Wnt-dependent stem cell niche. Nat Med 15: 701-706. doi:10.1038/nm.1951

Ormel PR, Vieira de Sá R, van Bodegraven EJ, Karst H, Harschnitz O, Sneeboer MAM, Johansen LE, van Dijk RE, Scheefnals N, Berdenis van Berlekom A, et al. 2018. Microglia innately develop within cerebral organoids. Nat Commun 9: 4167. doi:10.1038/s41467-018-06684-2

Ozone C, Suga H, Eiraku M, Kadoshima T, Yonemura S, Takata N, Oiso Y, Tsuji T, Sasai Y. 2016. Functional anterior pituitary generated in self-organizing culture of human embryonic stem cells. Nat Commun 7: 10351. doi:10.1038/ncomms10351

Paşca AM, Sloan SA, Clarke LE, Tian Y, Makinson CD, Huber N, Kim CH, Park JY, O’Rourke NA, Nguyen KD, et al. 2015. Functional cortical neurons and astrocytes from human pluripotent stem cells in 3D culture. Nat Methods 12: 671-678. doi:10.1038/nmeth.3415

Pollen AA, Bhaduri A, Andrews MG, Nowakowski TJ, Meyerson OS, Mostajo-Radji MA, Di Lullo E, Alvarado B, Bedolli M, Dougherty ML, et al. 2019. Establishing cerebral organoids as models of human-specific brain evolution. Cell 176: 743-756.e17. doi:10.1016/j.cell.2019 .01 .017

Qian X, Nguyen HN, Song MM, Hadiono C, Ogden SC, Hammack C, Yao B, Hamersky GR, Jacob F, Zhong C, et al. 2016. Brain-region-specific organoids using minibioreactors for modeling ZIKV exposure. Cell 165: 12381254. doi:10.1016/j.cell.2016.04.032

Qian X, Song H, Ming GL. 2019. Brain organoids: advances, applications and challenges. Development 146: dev 166074. doi:10.1242/dev.166074

Quadrato G, Nguyen T, Macosko EZ, Sherwood JL, Min Yang S, Berger DR, Maria N, Scholvin J, Goldman M, Kinney JP, et al. 2017. Cell diversity and network dynamics in photosensitive human brain organoids. Nature 545: 48-53. doi:10.1038/nature22047

Rathjen J, Haines BP, Hudson KM, Nesci A, Dunn S, Rathjen PD. 2002. Directed differentiation of pluripotent cells to 
neural lineages: homogeneous formation and differentiation of a neurectoderm population. Development 129: 2649-2661.

Renner M, Lancaster MA, Bian S, Choi H, Ku T, Peer A, Chung K, Knoblich JA. 2017. Self-organized developmental patterning and differentiation in cerebral organoids. EMBO J 36: 1316-1329. doi:10.15252/embj.2016 94700

Rothermel A, Willbold E, Degrip WJ, Layer PG. 1997. Pigmented epithelium induces complete retinal reconstitution from dispersed embryonic chick retinae in reaggregation culture. Proc Biol Sci 264: 1293-1302. doi:10.1098/ rspb.1997.0179

Sakaguchi H, Kadoshima T, Soen M, Narii N, Ishida Y, Ohgushi M, Takahashi J, Eiraku M, Sasai Y. 2015. Generation of functional hippocampal neurons from self-organizing human embryonic stem cell-derived dorsomedial telencephalic tissue. Nat Commun 6: 8896. doi:10.1038/ ncomms 9896

Sasai Y, Lu B, Steinbeisser H, Geissert D, Gont LK, De Robertis EM. 1994. Xenopus chordin: a novel dorsalizing factor activated by organizer-specific homeobox genes Cell 79: 779-790. doi:10.1016/0092-8674(94)90068-X

Sato T, Vries RG, Snippert HJ, van de Wetering M, Barker N, Stange DE, van Es JH, Abo A, Kujala P, Peters PJ, et al. 2009. Single Lgr5 stem cells build crypt-villus structures in vitro without a mesenchymal niche. Nature 459: 262 265. doi:10.1038/nature07935

Shi Y, Kirwan P, Livesey FJ. 2012. Directed differentiation of human pluripotent stem cells to cerebral cortex neurons and neural networks. Nat Protoc 7: 1836-1846. doi:10 $.1038 /$ nprot.2012.116

Shiraishi A, Muguruma K, Sasai Y. 2017. Generation of thalamic neurons from mouse embryonic stem cells. Development 144: 1211-1220. doi:10.1242/dev.144071

Sloan SA, Darmanis S, Huber N, Khan TA, Birey F, Caneda C, Reimer R, Quake SR, Barres BA, Paşca SP. 2017. Human astrocyte maturation captured in $3 \mathrm{D}$ cerebral cortical spheroids derived from pluripotent stem cells. Neuron 95: 779-790.e6. doi:10.1016/j.neuron.2017.07.035

Smith WC, Harland RM. 1992. Expression cloning of noggin, a new dorsalizing factor localized to the Spemann organizer in Xenopus embryos. Cell 70: 829-840. doi:10 .1016/0092-8674(92)90316-5

Steinberg MS, Gilbert SF. 2004. Townes and Holtfreter (1955): directed movements and selective adhesion of embryonic amphibian cells. J Exp Zool A Comp Exp Biol 301A: 701-706. doi:10.1002/jez.a.114

Steinberg MS, Roth SA. 1964. Phases in cell aggregation and tissue reconstruction an approach to the kinetics of cell aggregation. J Exp Zool 157: 327-338. doi:10.1002/jez .1401570304
Sutcliffe M, Lancaster MA. 2017. A simple method of generating 3D brain organoids using standard laboratory equipment. Methods Mol Biol 3: 519-512.

Tomooka Y, Kitani H, Jing N, Matsushima M, Sakakura T. 1993. Reconstruction of neural tube-like structures in vitro from primary neural precursor cells. Proc Natl Acad Sci 90: 9683-9687. doi:10.1073/pnas.90.20.9683

Vollmer G, Layer PG, Gierer A. 1984. Reaggregation of embryonic chick retina cells: pigment epithelial cells induce a high order of stratification. Neurosci Lett 48: 191-196. doi:10.1016/0304-3940(84)90018-1

Watanabe K, Kamiya D, Nishiyama A, Katayama T, Nozaki S, Kawasaki H, Watanabe Y, Mizuseki K, Sasai Y. 2005. Directed differentiation of telencephalic precursors from embryonic stem cells. Nat Neurosci 8: 288-296. doi:10 $.1038 / \mathrm{nn} 1402$

Watanabe K, Ueno M, Kamiya D, Nishiyama A, Matsumura M, Wataya T, Takahashi JB, Nishikawa S, Nishikawa S, Muguruma K, et al. 2007. A ROCK inhibitor permits survival of dissociated human embryonic stem cells. Nat Biotechnol 25: 681-686. doi:10.1038/nbt1310

Weiss P, Taylor AC. 1960. Reconstitution of complete organs from single-cell suspensions of chick embryos in advanced stages of differentiation. Proc Natl Acad Sci 46: 1177-1185. doi:10.1073/pnas.46.9.1177

Wilson H. 1907. On some phenomena of coalescence and regeneration in sponges. J Exp Zool 5: 245-258. doi:10 $.1002 /$ jez.1400050204

Wilson H. 1911. On the behavior of the dissociated cells in hydroids, alcyonaria, and Asterias. J Exp Zool 11: 281338. doi:10.1002/jez.1400110304

Xiang Y, Tanaka Y, Patterson B, Kang YJ, Govindaiah G, Roselaar N, Cakir B, Kim KY, Lombroso AP, Hwang SM, et al. 2017. Fusion of regionally specified hPSC-derived organoids models human brain development and interneuron migration. Cell Stem Cell 21: 383-398.e7. doi:10.1016/j.stem.2017.07.007

Xiang Y, Tanaka Y, Cakir B, Patterson B, Kim KY, Sun P, Kang YJ, Zhong M, Liu X, Patra P, et al. 2019. hESCderived thalamic organoids form reciprocal projections when fused with cortical organoids. Cell Stem Cell 24: 487-497.e7. doi:10.1016/j.stem.2018.12.015

Ying QL, Stavridis M, Griffiths D, Li M, Smith A. 2003. Conversion of embryonic stem cells into neuroectodermal precursors in adherent monoculture. Nat Biotechnol 21: 183-186. doi:10.1038/nbt780

Zhang SC, Wernig M, Duncan ID, Brüstle O, Thomson JA. 2001. In vitro differentiation of transplantable neural precursors from human embryonic stem cells. Nat Biotechnol 19: 1129-1133. doi:10.1038/nbt1201-1129 


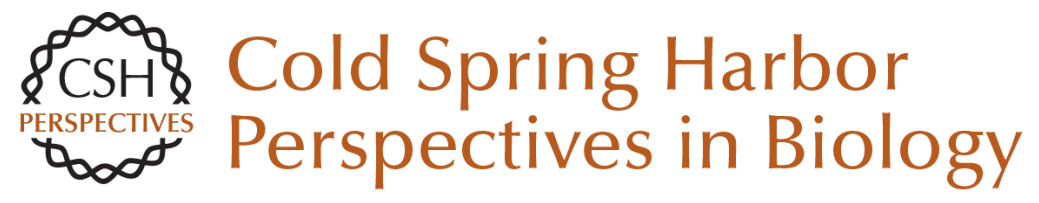

\section{Brain Organoids: Human Neurodevelopment in a Dish}

Silvia Benito-Kwiecinski and Madeline A. Lancaster

Cold Spring Harb Perspect Biol 2020; doi: 10.1101/cshperspect.a035709 originally published online November 25, 2019

\section{Subject Collection Stem Cells: From Biological Principles to Regenerative Medicine}

A Stem Cell Approach to Cure Type 1 Diabetes Aharon Helman and Douglas A. Melton

Niche Cells and Signals that Regulate Lung Alveolar Stem Cells In Vivo

Nicholas H. Juul, Courtney A. Stockman and Tushar J. Desai

Stem Cell DNA Damage and Genome Mutation in the Context of Aging and Cancer Initiation Lara Al zouabi and Allison J. Bardin

Capturing Stem Cell Behavior Using Intravital and Live Cell Microscopy

Arianna Fumagalli, Lotte Bruens, Colinda L.G.J. Scheele, et al.

Brain Organoids: Human Neurodevelopment in a Dish

Silvia Benito-Kwiecinski and Madeline A. Lancaster

Advancing Stem Cell Research through

Multimodal Single-Cell Analysis

Iwo Kucinski and Berthold Gottgens

Tracing the Dynamics of Stem Cell Fate

Lemonia Chatzeli and Benjamin D. Simons
Mouse Spermatogenesis Reflects the Unity and Diversity of Tissue Stem Cell Niche Systems Shosei Yoshida

A Synthesis Concerning Conservation and Divergence of Cell Types across Epithelia Daniel T. Montoro, Adam L. Haber, Jennifer E. Rood, et al.

Discovering New Progenitor Cell Populations through Lineage Tracing and In Vivo Imaging Rudra Nayan Das and Karina Yaniv

Next-Generation Biomaterials for Culture and Manipulation of Stem Cells

Koichiro Uto, Christopher K. Arakawa and Cole A. DeForest

Development of Stem Cell Therapies for Retinal Degeneration Emma L. West, Joana Ribeiro and Robin R. Ali

Direct Lineage Reprogramming: Harnessing Cell

Plasticity between Liver and Pancreas Silvia Ruzittu, David Willnow and Francesca M. Spagnoli

Modeling Brain Disorders Using Induced

Pluripotent Stem Cells Krishna C. Vadodaria, Jeffrey R. Jones, Sara Linker, et al.

For additional articles in this collection, see http://cshperspectives.cshlp.org/cgi/collection/

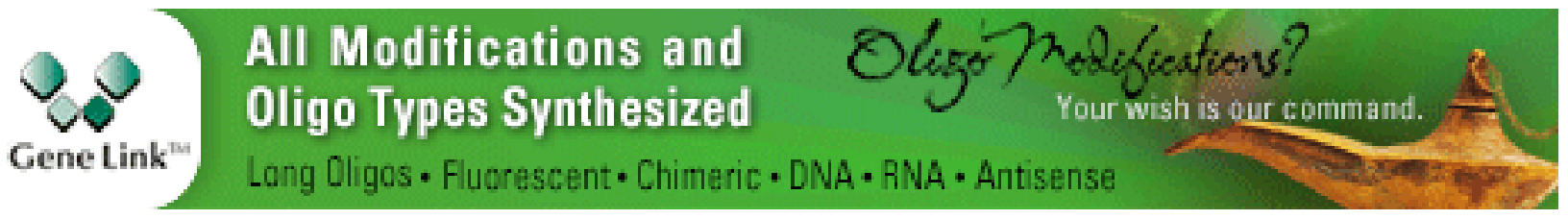


Toward Combined Cell and Gene Therapy for

\section{Genodermatoses}

Laura De Rosa, Maria Carmela Latella, Alessia Secone Seconetti, et al.

\section{Specification of the First Mammalian Cell \\ Lineages In Vivo and In Vitro \\ Melanie D. White and Nicolas Plachta}

For additional articles in this collection, see http://cshperspectives.cshlp.org/cgi/collection/

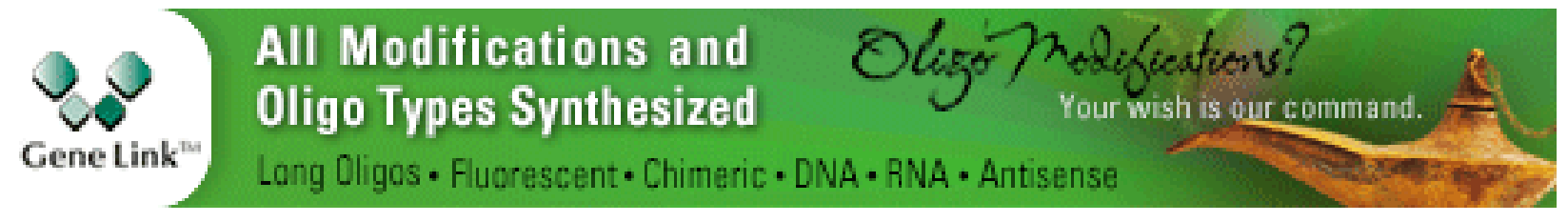

Copyright @ 2020 Cold Spring Harbor Laboratory Press; all rights reserved 